\title{
METHODOLOGY FOR DECREASING THE LEVEL OF RISK IN WORKPLACES WITH THE OCCURRENCE OF FINE AND ULTRAFINE PARTICLES.
}

\author{
${ }^{1}$ Klaudia KÖBÖLOVÁ, ${ }^{1}$ Vladimír ADAMEC, ${ }^{1}$ Michal URBÁNEK, ${ }^{2}$ Tomáš ZEMAN, \\ 'Jana DRBOHLAVOVÁ \\ ${ }^{1}$ Brno University of Technology, Institute of Forensic Engineering, Brno, Czech Republic, EU, \\ Klaudia.Kobolova@vutbr.cz,Vladimir.Adamec@vut.cz, Michal.Urbanek2@vutbr.cz,xcchovancova@vut.cz \\ ${ }^{2}$ University of Defence, Faculty of Military Leadership, Brno, Czech Republic, EU, tomas.zeman2@unob.cz
}

https://doi.org/10.37904/nanocon.2021.4315

\begin{abstract}
With the development of new technologies, the requirements for safety and health at workplaces are also increasing. One of these sectors are also industrial plants which process or use fine and ultrafine particles $(<2.5 \mu \mathrm{m})$ during their activities or where these particles are created unintentionally as a by-product of the production processes. In the case of risk assessment of these particles, it is not only a matter of health risks associated with direct exposure to these particles but can have negative effects on mental health of employees. This could lead to stress, increase mental discomfort, reduce attention, performance, and motivation to work. The aim of the methodology is to evaluate the health and safety management system, increase its level and efficiency in operations loaded with fine and ultrafine particles. The methodology includes both the assessment of risks associated with the exposure of workers and the rate of perception of risks by employees in the field of information about the risks associated with fine and ultrafine particles. It also includes perception of the adequacy of existing safety measures to reduce worker exposure to these particles. The proposal of basic measures to reduce exposure of workers is also an integral part of methodology. The proposed methodology is in line with OECD guidelines focused on nanosafety.
\end{abstract}

Keywords: OSH, PM1, UFP, health, workplace

\section{INTRODUCTION}

The aim of occupational safety and health $(\mathrm{OSH})$ is to ensure that the working environment is such that the safety risks to employees are minimised. The general principles of OSH include the overall company strategy (legislation, tasks and objectives, programmes, systems of evaluated objects), identification, analysis and evaluation of hazards, control, and corrective measures (monitoring, inspections, prevention, records, audits, etc.), continuous identification of achieved results (external and internal) and their comparison with expected results [1,2]. A functional safe work environment policy is also based on ensuring the socio-technical system, which includes people (employees) with all their characteristics (education, ambition, reliability, etc.) [3-5].

With the development of technology, the demand for the level of OSH is also increasing and new areas are emerging, especially in industry, where sufficient safety and preventive measures are not yet provided. One of these sectors are industrial plants that process or use fine and ultrafine particles (size up to $2.5 \mu \mathrm{m}$ ) in their operations, or where these particles are unintentionally generated as a by-product of the manufacturing processes used [6]. Outside of industrial plants, there are work processes where nanomaterials are applied, such as spraying or coating titanium dioxide and nanosilver. Direct exposure to these particles can have a severe impact on human health [7,8]; thanks to their small size they can carry toxic substances and reach deeper into the human respiratory system [9]. But in the case of risk assessment of fine and ultrafine particles (FP and UFP), it is not only the health risks associated with direct exposure to these particles. Working in an 
environment where FP and UFP are present can also have negative effects on the mental health of the employee [10]. These psychological effects are mainly related to the employee's subjective perception of the level of safety in a work environment with FP and UFP. If this level is inadequate from the employee's point of view, it can lead to stress, increased psychological discomfort, reduced attention, performance, and motivation to work. However, secondary risks should also be considered in the context of $\mathrm{OSH}$, such as the impact on the operation of the company and its economy associated with reduced employee efficiency and productivity due to safety measures, increased sickness, and absenteeism [11].

One major and important challenge is to reliably assess the risks and safety of FP and UFP. The main problem is the lack of systematic knowledge about the exposure of these particles, the lack of limit values, and the lack of knowledge about the impact on human health and the environment. Currently, there is no specific guideline that addresses the OSH management system in workplaces burdened by FP and UFP. The Occupational Safety Research Institute in the Czech Republic has developed a certified methodology for the provision of personal protective equipment in nanoparticle hazardous environments [12], which, as the name implies, addresses only the allocation of personal protective equipment for respiratory protection. Due to these facts, a methodology for better OSH management was developed mainly for the Czech Republic.

\section{BACKGROUND}

Development a suitable methodology for FP and UFP is very difficult because the health effect of these particles is determined by their several properties, not just by their concentration. In contrast to particles with larger dimensions, the sedimentation level of UF and UFP in the air due to gravity is very low to negligible [13]. For this reason, these particles may persist in the workplace air for several days. Thus, the Organisation for Economic Co-operation and Development (OECD) [14] recommends for the monitoring of FP and UFP in the work environment their long-term measurement. The interaction of these particles with other airborne substances may not be stable over the long term and may become re-release from these bonds.

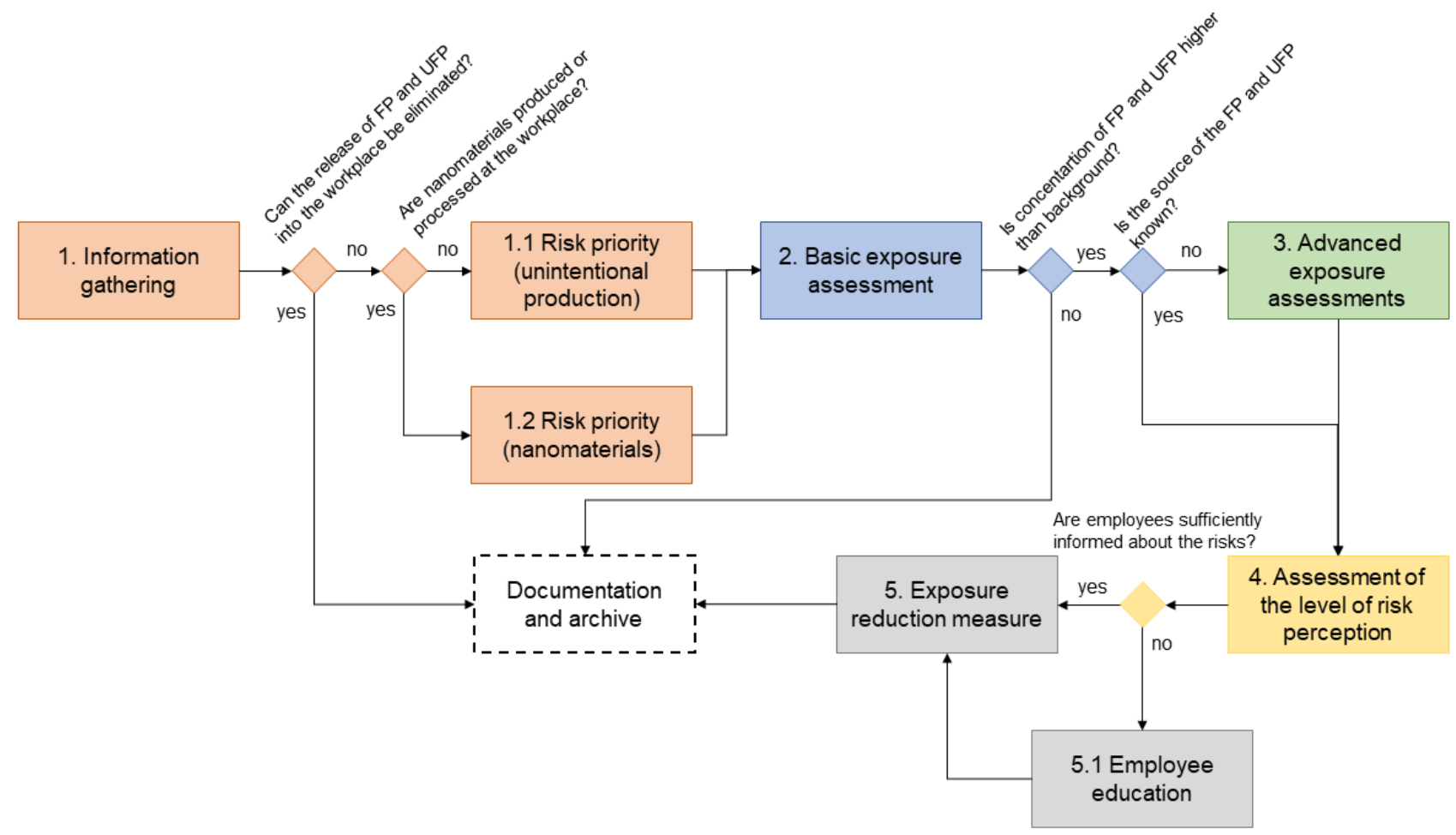

Figure 1 Scheme of methodology to manage risks of FP and UFP 
Our methodology is based on the OECD nanosafety procedure [14]. The methodology aim is to evaluate the $\mathrm{OSH}$ management system, to increase its level and efficiency in companies dealing with particles with aerodynamic diameter $<2.5 \mu \mathrm{m}$. It consists of several chapters, which first focus on workplace characterisation and risk prioritisation based on the knowledge obtained from the workplace documentation. The next two sections deal with basic and advanced exposure assessment according to the OECD methodology. According to the assessment, the level of risk perception of the workers is assessed, and a summary risk assessment is produced. The last section describes proposals for measures to reduce employee exposure.

\section{METHODOLOGY FOR OSH MANAGEMENT}

The methodology based on a five-step procedure (see in Figure 1) consists of the following steps: information gathering, basic exposure assessment, advanced exposure assessments, assessment of the level of risk perception by employees, and measures.

\subsection{Information gathering}

The first step is the characterisation of the workplace. It should be based primarily on a study of the documentation, or a personal inspection of the workplace, to identify possible sources of FP and UFP at the workplace. These main indicators should be investigated depending on the type of production processes as information on the workplace, the size of the workplace and production areas, the characteristics and properties of the produced or processed FP and UFP, an overview of workplace processes that may generate FP and UFP as a by-product, an overview of workplace processes that may affect the measurement of FP and UFP concentrations, the current status of exposure reduction measures (personal protective equipment (PPE) or the ventilation technology) and risk characterisation (synthesis of the knowledge gained in this step).

The first step aim to answer the question if there is a possibility to eliminate the release of FP and UFP into the work environment by prioritising the risk. Further, it is necessary to determine if nanomaterials are produced or processed at the workplace or FP and UFP are expected to occur during their unintentional production. If nanomaterials are produced or processed in the workplace, it is recommended to use the Risk and Control Banding tool for risk prioritising, such as the Stoffenmanager Nano tool $[15,16]$. The tool assesses the exposure level and the risk level, and risk priority according to a combination of these levels (see Figure 2). If determined priority is 1 or 2 , that must be continuing step 2 . On the other hand, nanomaterials with priority 3 proceed to the assessment of the level of risk perception of employees. In the case of the possible generation of FP and UFP by unintentional processes proceeds to step 2.

\begin{tabular}{|c|c|c|c|c|c|}
\hline Hazard band & A & B & C & D & E \\
\hline Exposure band & 3 & 3 & 3 & 2 & 1 \\
\hline 1 & 3 & 3 & 2 & 2 & 1 \\
\hline 2 & 3 & 2 & 2 & 1 & 1 \\
\hline 3 & 2 & 1 & 1 & 1 & 1 \\
\hline 4 & & & & & 1 \\
\hline
\end{tabular}

Hazard band: $A=$ lowest hazard, $E=$ highest hazard. Exposure band: 1=lowest exposure, 4=highest exposure. Overall result: $1=$ highest priority, $3=$ lowest priority

Figure 2 Example for risk priority determination in Stoffenmanager Nano tool [17]

\subsection{Basic exposure assessment}

This part contains an initial measurement of FP and UFP in the workplace. The measurements shall be carried out continuously for at least one working shift, starting at least 30 minutes before the start of the processes. At 
the same time, all processes and other activities carried out during the measurement, including the use of PPE by workers, must be recorded. For each employee, the time of entry to and exit from the workplace shall be recorded. For measurements could use any instrument with a valid certified calibration capable of continuously recording the number concentrations of FP and UFP within the selected particle size range. It is recommended that the measured particle size range be selected based on an evaluation of the information on the nanomaterial or the manufacturing activity obtained in the previous. If the size range cannot be determined, it is recommended to use a size range between $10 \mathrm{~nm}$ and 500 .

If measured concentrations of FP and UFP are higher compared to background concentrations, then proceeds step 3, which is advanced exposure assessment. Step 3 should have proceeded if the difference between the mean concentration of FP and UFP $\left(\mathrm{MC}_{1}\right)$ in the work environment and the mean background concentration $\left(\mathrm{MC}_{0}\right)$ is greater than three times the standard deviation of the background concentrations $\left(\mathrm{SD}_{0}\right)$ of $\mathrm{FP}$ and UFP (see equation 1).

$\mathrm{MC}_{1}-\mathrm{MC}_{0}>3 \mathrm{SD}_{0}$,

The output of basic exposure assessment is a record that contains the time series of the measured data, the means and standard deviations of the concentrations of FP and UFP at the measurement site and in the background, information activities that could affect the distribution, photo documentation and basic descriptions of microclimatic parameters, information on the times of entry and exit of workers from workplaces and statistical tests of the difference in concentrations in the working environment compared to background.

\subsection{Advanced exposure assessment}

The objective of advanced exposure measurement is to identify the source of FP and UFP in the workplace and to characterise these particles (composition, size, and shape of the identified particles). For this purpose, it is necessary to use advanced instruments for measuring FP and UFP, in particular [14]:

- $\quad$ instruments using particle mobility measurements in an electric field, e.g. Scanning Mobility Particle Sizer (SMPS);

- $\quad$ optical or aerodynamic particle counters;

- $\quad$ Electrical Low-Pressure Impactor (ELPI);

- $\quad$ Condensation Particle Counter (CPC).

This step always needs to be customised to the situation at the workplace, thus no universal procedure can be established in advance. To determine the correct procedure, it is necessary to rely on the previous baseline exposure assessment and the characteristics of the workplace. Alternatively, it is possible to follow the standard ISO 14644:2015 [18].

If the advanced exposure assessment leads to the successful identification of the source of FP and UFP in the workplace and the characterisation of these particles is carried out, the results obtained can be used to design exposure reduction measures. Regardless of whether the identification and characterisation of the source of FP and UFP in the workplace is successful in this step, an assessment of the level of risk perception by workers is then undertaken.

\subsection{Assessment of the level of risk perception of employees}

This section has two parts, the identification of the level of the risk via questionnaire and the overall risk assessment. The questionnaire is used to assess the level of risk perception associated with inhaled FP and UFP by employees working in operations where these particles are present. The questionnaire asks for the following topics: level of awareness of employees of the risks of exposure to FP and UFP during work, adequacy of existing safety measures to reduce worker exposure FP and UFP in the workplace. Further step 
depends on the employees' answers if they have knowledge about FP and UFP. If all the employees answer 'YES' to this question, the risk assessment then proceeded to an overall risk assessment. If any of the employees' answer 'NO' to this question, the implementation of the measure proceeds directly.

The overall risk assessment aggregate information about the level of employee awareness of the risks of exposure and level of perception of the adequacy of existing safety measures. The priority risk level ranges from 1 to 3 . If the identified risk level is 2 and 3 it is recommended to introduce regular training/education of workers about risks associated with exposure to FP and UFP. If the priority is 1 no action is required in concerning the training of employees. Regardless of the outcome of the overall risk assessment, it should be an implementation of exposure reduction measures.

\subsection{Measures and controlling}

If measured concentrations of FP and UFP are higher (according to equation 1), the associated risks can be reduced by taking appropriate measures. The following measures are the most effective in terms of inhaled FP and UFP:

- $\quad$ process isolation or local ventilation;

- $\quad$ training of workers;

- $\quad$ use of personal protective equipment;

- $\quad$ operational measures.

After implementation of the selected exposure reduction measures, it is recommended to return to basic exposure measurements (see Figure 1). If, as a result of the measures taken, the number has been reduced to an acceptable level according to equation 1, it is recommended that the information obtained in each step of this methodology document and archive. Otherwise, the process should be repeated until the number of concentrations is reduced below the required limit according to equation 1. Once this objective is achieved, it is recommended, by the OECD recommendation [14], to repeat the whole procedure every two years or in case of a change in the processes at the workplace.

\section{CONCLUSION}

The methodology is focused on OSH management to address the need to increase the level and efficiency of $\mathrm{OSH}$ in operations with particulate matter size up to $<2.5 \mu \mathrm{m}$. The methodology can also be used by employers in workplaces exposed to FP and UFP to develop measures to reduce employee exposure and to assess the level of employee risk perception.

\section{ACKNOWLEDGEMENTS}

This paper is supported by TA ČR within the TL02000240 project of Increasing the Level of OSH Management in Workspace with Occurrence of Fine and Ultrafine particles.

\section{REFERENCES}

[1] AVEN, T. "Risk assessment and risk management: Review of recent advances on their foundation." European Journal of Operational Research. 2016, vol. 253, no. 1, pp. 1-13.

[2] ISO 45001:2018. Occupational health and safety management systems - Requirements with guidance for use, 2018.

[3] AVEN, T. and YLÖNEN, M. "A risk interpretation of sociotechnical safety perspectives." Reliab. Eng. Syst. Saf. 2018, vol. 175, pp. 13-18. 
[4] AVEN, T. "How some types of risk assessments can support resilience analysis and management." Reliab. Eng. Syst. Saf. 2017, vol. 167, pp. 536-543.

[5] CARAYON, P., HANCOCK, P., LEVESON, N., NOY, I., SZNELWAR, L. and VAN HOOTEGEM, G. "Advancing a sociotechnical systems approach to workplace safety - developing the conceptual framework." Ergonomics. 2015, vol. 58, no. 4, pp. 548-564.

[6] VAN BROEKHUIZEN, Pieter, VAN BROEKHUIZEN, Fleur, CORNELISSEN Ralf a Lucas REIJNDERS. Workplace exposure to nanoparticles and the application of provisional nanoreference values in times of uncertain risks. Journal of Nanoparticle Research [online]. 2012, 14, vol. 4. Available from: https://doi.org/10.1007/s11051-012-0770-3. ISSN 1388-0764.

[7] SCHRAUFNAGEL, Dean E. The health effects of ultrafine particles. Experimental \& Molecular Medicine. [online]. 2020, vol. 52, no. 3, pp. 311-317. ISSN 1226-3613. Available from: https://doi.org/10.1038/s12276-020-0403-3

[8] SHARMA, Shubham, CHANDRA, Mina a KOTA, Sri Harsha. Health Effects Associated with PM2.5: a Systematic Review. Current Pollution Reports. [online]. 2020, vol. 6, no. 4, pp. 345-367. ISSN 2198-6592. Available from: https://doi.org/10.1007/s40726-020-00155-3

[9] TIAN, Guoxiong, WANG, Juan, LU, Zhongbing, WANG, Hongyun, ZHANG, Wei, DING, Wenjun a ZHANG, Fang. Indirect effect of PM1 on endothelial cells via inducing the release of respiratory inflammatory cytokines. Toxicology in Vitro. [online]. 2019, vol. 57, pp. 203-210. ISSN 08872333. Available from: https://doi.org/10.1016/j.tiv.2019.03.013

[10] BRUGGE, Doug a FULLER, Christina H. Ambient Combustion Ultrafine Particles and Health. 1. Nova Science Publishers, 2021. ISBN 978-1-53618-831-8.

[11] BAYRAM, Metin a BURGAZOGLU, Huseyin. The Relationships Between Control Measures and Absenteeism in the Context of Internal Control. Safety and Health at Work. [online]. 2020, vol. 11, no. 4, pp. 443-449. ISSN 20937911. Available from: https://doi.org/10.1016/..shaw.2020.07.007

[12] Occupational Safety Research Institute. Methodology for providing personal protective equipment in an environment with a risk of nanoparticles. [online]. Prague, 2016, p. 23. Certificated methodology. In: https://www.mpsv.cz/documents/20142/225499/Metodika pro poskytovani OOP v prostredi s rizikem vyskytu nanocastic.pdf/260c679b-9a39-4734-12cd-79736892d095

[13] HINDS, William C. Aerosol technology: properties, behavior, and measurement of airborne particles. 2nd ed. New York: John Wiley, c1999. A Wiley-Interscience publication. ISBN 978-0-471-19410-1.

[14] OECD: Harmonized tiered approach to measure and assess the potential exposure to airborne emissions of engineered nano-objects and their agglomerates and aggregates at workplaces, 2015. [online]. In: https://www.oecd.org/officialdocuments/publicdisplaydocumentpdf/?cote=env/jm/mono(2015)19\&doclanguage=en

[15] MARQUART, H. HEUSSEN, H. LE FEBER, M. NOY, D. TIELEMANS, E. SCHINKEL, J. WEST, J. and VAN DER SCHAAF, D. "'Stoffenmanager', a Web-Based Control Banding Tool Using an Exposure Process Model." The Annals of Occupational Hygiene. 2008, vol. 52, no. 6, pp. 429-441.

[16] VAN DUUREN-STUURMAN, B., VINK, S. R., VERBIST, K. J. M., HEUSSEN, H. G. A., BROUWER, D. H., KROESE, D. E. D., VAN NIFTRIK, M. F. J., TIELEMANS, E. and FRANSMAN, W. "Stoffenmanager Nano Version 1.0: A Web-Based Tool for Risk Prioritization of Airborne Manufactured Nano Objects." The Annals of Occupational Hygiene. 2012, vol. 56, no. 5, pp. 525-541.

[17] VÄÄNÄNEN V, RYDMAN E, ILVES M, HANNUKAINEN K, NORPPA H, VON WRIGHT A, et al. Evaluation of the suitability of the developed methodology for nanoparticle health and safety studies. Sunpap conference; [online]. 2012. http://sunpap.vtt.fi/pdf/SUNPAP WP10 DEL10 520120827 FIOH.pdf.

[18] ISO 14644-1:2015 Cleanrooms and associated controlled environments - Part 1: Classification of air cleanliness by particle concentration, 2015. 